\title{
Sosyal Medya ve Linç Kültürü
}

\author{
Social Media and Lynch Culture
}

Sertaç Timur Demir, Doç. Dr., Gümüşhane Üniversitesi İletişim Fakültesi, E-posta: stdemir@yahoo.com Ali Özcan, Dr. Öğr. Üyesi, Gümüşhane Üniversitesi İletişim Fakültesi, E-posta: aliozcan@gumushane.edu.tr

https://doi.org/10.47998/ikad.957544

\author{
Sosyal Medya, \\ Linç, \\ Kitle, \\ Cep Telefonu, \\ Modern Kültür.
}

Anahtar Kelimeler:
Keywords:

Social Media, Lynching,

Mass,

Mobile Phone, Modern Culture.

\section{$\ddot{O} z$}

Bu makalede özellikle ifade özgürlüğü, engelsiz iletişim ve sınırsız paylaşım vaatleriyle gündelik yaşama giren, fakat kısa süre içinde neredeyse tüm ilişki ve deneyimleri kendine uyarlayan sosyal medyanın, kitlesel nefret ve tekinsizlik mecrasına evrildiği öne sürülmektedir. Ayrıca etkileri sanal, sonuçlarıysa gerçek olan linç kültürünün yükselişi olarak beliren bu keskin dönüşümün gölgesinde, kullanıcıların küresel ağın kaçınılmaz bir parçası oldukları düşünülmektedir. Buna göre, bu mecradaki yanılsamalı soyutluğun aksine, kullanıcıların arkalarında bıraktıkları dijital izler kalıcıdır ve silinemez. Bu nedenle bir zamanlar kitlelerin anonimliğine sığınarak kolektif linçin öznesi olan kişiler, her an aynı kitlelerin hedefi olabilmektedir. Dolayısıyla bu siber-uzamda metinler bağlamından çıkarıldığında, konjonktür değiştiğinde veya kişisel veriler öngörülemez biçimde gasp edildiğinde, kusursuz ve pürüzsüz sanılan tüm gidişat ansızın tersine dönebilmektedir. Bu ikircikli durum, kitlenin ve kendine özgü kitle dokusunu üreten sosyal medyanın önceden tanımlanagelen meşruiyet gerekçelerinin ötesinde, hesaba katılmayan yansıması ve yaygın trendidir. Sosyal medyada kullanıcılar; yaptığı her paylaşımın ve girdiği her sitenin adeta bir rehinesidir. Bu araştırmada söz konusu sorunsal; popüler bilim kurgu yapımı olan Black Mirror dizisinin "Sosyal Linç” bölümü üzerinden sanal linç, dijital kitleler ve mobil teknolojiler bağlamında analiz edilmesidir . Dijital beşeri bilimler kapsamında yürütülen bu disiplinlerarası çalışmanın çatısı, meseleye güçlü açılımlar sunan Zygmunt Bauman, Jean Baudrillard ve Byung Chul-Han gibi düşünürlerin teorileri etrafinda yapılandırılmıştır.

\section{Abstract}

In this article, it is argued that social media, which enters daily life with the promises of freedom of expression, unhindered communication and unlimited sharing, but adapts nearly all relationships and experiences to itself in a short time, has evolved into a medium of mass hatred and uncanny. It is also claimed that the users are an inevitable part of the global network in the shadow of this sharp transformation, which appears as the rise of the lynching culture, whose causes are virtual and the consequences are real. Accordingly, contrary to the illusory abstraction in this medium, the digital traces that users leave behind are permanent and indelible. For this reason, people who were once the subject of collective lynching by taking refuge in the anonymity of the masses can be the target of the same masses at any time. In other words, in this cyber-space, when the texts are taken out of their context; when the conjuncture changes or when personal data is hacked in an unpredictable manner, the whole course of events that was once considered perfect and smooth can suddenly reverse. This ambiguous situation is the unaccounted reflection and widespread trend of the mass and social media, which produces its own notion of mass, beyond the pre-defined justifications. In social media, users are the hostage of each post they make and each website they visit. In this research, this problematic is analysed through the episode of Hated in the Nation of the popular science fiction series Black Mirror and in the context of virtual lynching, digital masses and mobile technologies. The framework of this interdisciplinary study, which is based on digital humanities approaches, is structured around the theories of thinkers such as Zygmunt Bauman, Jean Baudrillard and Byung Chul-Han who offer stimulating perspectives on the issue. 


\title{
Giriş: A ̆g’a Yakalanan İnsan
}

\author{
Bir bilimkurgu öyküsünde, çok zengin birkaç kişi lüks dağ evlerinde \\ bir sabah uyandıklarında kendilerini saydam ve aşılmaz bir engelle, \\ geceleyin ortaya çıkmış bir cam duvarla kuşatılmış olarak bulur. \\ Camla çevrili bu konforlu derin yerden dış dünyayı; koptukları gerçek, oysa ansızın \\ yeniden ideal olmuş dünyayı yine de az çok görürler. Ama artık çok geçtir. \\ Bu zengin insanlar akvaryumları içinde kırmızı balıklar gibi yavaş yavaş ölecektir.
} Jean Baudrillard (2013: 57)

Modern insanın gittikçe sınırsızlaşan bir ağ kültürüyle irtibatlı olduğu yaklaşık elli yıldır tartışılmaktadır. Bu insan irtibatlı ağ ister "ağ şehri" [The Network City] (Craven ve Wellman, 1973), ister "kablolu toplum" [the wired society] (Martin, 1978), ister "ağ ulusu" [the network nation] (Hiltz ve Turoff, 1978) ve isterse "ağ toplumu" [the network society] (van Dijk, 1991; Castells, 1996) olarak tanımlansın, teorilerin her biri farklı etki düzeylerinde de olsa toplumsal değişimin merkezine; ağları yerleştirmektedir. Gelinen noktada toplumla ağ arasında artık birbirinden ayrı düşünülebilecek iki karşıt parametrenin ilişkisi yerine, neredeyse birbirinin yerini alan ontolojik iç içelik ve çiftyönlü benzeşim söz konusudur. Bu girift durum, modern insanın artık her an bir ağa bağlı olmasıyla ve gündelik yaşamını bu ağın sağladığı inovatif konfor etrafında inşa etmesiyle ilgilidir. Leonhard (2018: 181)'ın dediği gibi, çevrimdışı uzaklıklarda dijital detoks yapma lüksüne sahip olanlar dışında, artık her şey ve herkes bir ağa bağlıdır. Belki de modern insan; ağın kendisidir.

DataReportal'ın We Are Social ve Hootsuite ortaklığıyla yayınlanan Digital 2021 raporuna göre Ocak 2021 itibariyle 7.83 milyar olan dünya nüfusunun yüzde 66.6's1 (5.22 milyar kişi) cep telefonu sahibi olup, yüzde \%59.5'i (4.66 milyar kişi) internet ve \%53.6'sı (4.20 milyar kişi) aktif sosyal medya kullanıcısıdır. Son bir yıl içinde sosyal medya kullanıcıları \%13 oranında (490 milyon kişi) artmıştır. Sosyal medya kullanıcılarının \%98.8'inin cep telefonu bulunmaktadır (datareportal.com, 2021). İnternet, sosyal medya ve cep telefonu kullanımında gözlemlenen artış, yalnızca nicel bir değişime gönderme yapmamakta, modern toplumun ne denli devasa bir ağın parçası olduğuna da vurgu yapmaktadır. Ekranlar, Virilio (2003: 20)'nun tespit ettiği gibi, küreselleşmenin sanallaştırılan ufkunun seyredildiği pencerelere dönüşmektedir. Fakat Virilio'nun tasvirindeki siber-uzamda hala gözün sahibi ile ekran arasında bir mesafe olduğu varsayılmaktadır. Oysa bugün göz ile ekran arasındaki mesafe olabildiğince kapanmış, dahası birbiri içine geçmiştir. Bu evrenin bedensiz ve suretsiz kullanıcıları, Le Breton (2016)'un dikkat çektiği gibi, klavyeden başka dokunma organı ve ekrandan başka gözün olmadığı bu engin dünyada kesintisiz kesişmelere yakalanmaktadır.

$\mathrm{Bu}$ ekran-kesişmeleri dış dünyanın ve mekansal tasarımın ayırt edici dokusunu deforme etmektedir. Çünkü ağın ortasında yaşanan her şey nereden bakılsa artık bir h/iç- 
mekan deneyimini resmetmektedir. Günther Anders (2018b: 258) dünyanın evlere servis edildiği düzenden, evlerin dünyaya servis edildiği düzene geçildiğini uzun y1llar evvel yazdıktan sonra, artık bir hayalet olan dış dünyanın evlerdeki masif duvarları aştığından bahsetmektedir. Öte yandan dış dünyayı hayaletleştiren ağlar, evleri de aile içi yakınlığın mezarlığına, yani salt mimariye indirgemektedir. Evler odalara, odalar insanlara, insanlar ekranlara, ekranlar da ağlara uygun olarak parçalanmaktadır. İnternetin uzamı -ki yönsüz ve yüzergezer bir uzamdır bu (Han, 2019a: 50)- kendi dışında neredeyse başka bir uzam bırakmayacak şekilde sonsuzluk isteğini taşıyan bir iştahla genişlemektedir ${ }^{1}$. Fakat internet uzamında bu sonsuz genişlemeci tavrın aksine, herhangi bir insani tekamül yaşanmamakta, buradaki zaman fragmanları da birikmeyen şimdi'lerden oluşmaktadır. Han (2019a: 51), can sıkıntısına neden olduğunu söylediği bu "uzatılmış bulunma”yı, "süreksiz ve noktalı bir şimdi zamanı" olarak tanımlamaktadır.

Yaşadığımız kültürü bir bütün olarak "hınç kültürü” olarak etiketleyen Baudrillard (2001: 81), bu yıkım-döngüsünü şöyle ifade etmektedir: "Aynı kültürün içinde, ötekine duyulan hıncın arkasında, kendimize karşı duyulan hıncın, kendimizin ve benzerin diktatoryasına karşı duyulan hıncın olduğunu tahmin etmek gerekir ve bu hınç kendi kendimizin yıkımına dek gidebilir". Le Breton (2016: 222) da interneti, kendilerine hınç duyanların teni ve sinir sistemi olarak görmektedir. Fakat yine de bu, özgür iradesi kısmen ya da tamamen felce uğramış bir sinir sistemidir. Aynı minvalde Richard Sennett (2013: 365), pasifliğin kitlesel medya teknolojilerinin mantığında olduğunu ve insanları izledikleri şey karşısında sessiz kalmaya zorladığını savunmaktadır. Şüphesiz tek yönlü geleneksel medya için bu tespit bir noktaya kadar doğrudur. Ancak yeni dijital medya, gelenekselin aksine fazlasıyla katılımcıdır. Fakat onun sorunu da bu katılımın aşırı ve devamlı, hatta çoğu kez mecbur olmasıdır. Bu kesintisizlik, esasında aktif görünen kullanıcıların orta ve uzun vadedeki kaçınılmaz pasifliğinin özüdür. Dahası onlar, burada pasif olduklarını fark edebilecekleri bir tefekkür anı ve alanından mahrumdurlar. Ne var ki bu mahrumiyete neden olan sanal meşguliyet; verimsiz, üretimsiz ve çıkarımsızdır. Yeni medyadaki aktiflik yanılgısı, tam olarak bu sahte koşuşturmacanın tek mahsulüdür.

\section{Yaklaşım ve Yöntem}

Bu nitel çalışma, disiplinlerarası yaklaşımla bilim kurgu kültürünün işaret ettiği tekno-toplumsal izleği takip etmektedir. Bir zamanlar spesifik takipçileri olan bilim kurgu, gün geçtikçe -özellikle pandemiyle birlikte- kitleselleşmiş ve küresel değişimi anla(t)manın bir aracına dönüşerek popülerleşmiştir. Diğer bir ifadeyle, yaşanan pandemi, yıllardır filmlerde gösterilen kurgunun çok da akıl dışı olmadığını ortaya koymuştur. Buna göre sanki filmler hayattan alınmış gibi değil de; ilginç bir şekilde sanki hayat filmlere öykünür gibi durmaktadır. Bu anlamda filmleri, toplumsal işleyişin salt projektörü (Diken ve Laustsen, 2008) olarak değil, tasarımcısı olarak görmek de mümkündür. Üstelik filmler üzerine yoğunlaşan analizci hangi uzmanlık alanından olursa olsun, ona kendi alet çantasını kullanabilmesine imkan da tanımaktadır (Sutherland ve Kathryn, 2013).

1 "Teknoloji Toplumu" kitabında Jacques Ellul, kitleleri içeren ve hiçbir bireyin dışında kalamayacağı teknik genişlemenin, mümkün olan en geniş alanı istediğinden ve bunun sonucu olarak da yakın gelecekte - ki muhtemelen o gün bugündür - yerkürenin tamamının bile yetersiz kalacağından bahsetmektedir (2003: 222). 
Son dönem sosyal ve beşeri bilimlerinin çeşitli alanlarından çok sayıda teorisyenin filmlere odaklanması bu nedenle anlaşılır bir eğilimdir. Bu çalışmada ise; filmin kendisi değil, onun sosyal medya ve linç olgusuna temas eden düşünsel ima ve göndermelerine odaklanılmaktadir.

Bilim kurgu olağandışı veya imkansız olayların tasvir edildiği bir düşsellik olmaktan çıkarak, çağdaş sinemanın belki de en gerçekçi türlerinden birisine dönüşmüştür (Demir, 2021: 91). Özellikle yaşadığımız asrın yaşanması çok muhtemel trajedilerinin ipuçları ve olası sonuçları, bilim kurgu filmlerinde açıkça karşılık bulmaktadır. Black Mirror'ın yapımcısı Charlie Brooker (2011)'da dizinin bölümleri hakkında konuşurken verdiği demeçte aynı gerçekliğin altını çizmiştir: "Bölümlerin hepsi şimdi nasıl yaşadığımızla ve beceriksiz olursak on dakika içinde nasıl yaşayacağımızla ilgili. Ve eğer insanlık hakkında bildiğimiz bir şey varsa, o da şudur: Genellikle sakarız". Black Mirror'ın bu makalede incelenen epizotu Sosyal Linç de (2016), yine Brooker'ın deyimiyle "Bir tür yapay mesafe yaratıyor gibi görünen sosyal medya dünyasında ne kadar sorumluluk alıyorum?" sorusunun izini sürmektedir (Brooker vd., 2018: 218). Sosyal medyada şiddet konusunu ele alan Hatice Turan da (2017: 130), "Sosyal Linç" bölümünü tahlil ederken; sosyal medyadaki basit bir tıklamanın neden olduğu linç ile yine tek bir hamleyle gerçekleştirilen kitlesel ölümler arasında bağıntı kurmaktadır.

\section{Filme Dair}

"Sosyal Linç" filmi, engelli bir kadın hakkında yazdığı yazı nedeniyle aleyhinde imza kampanyası başlatılan ve sosyal medyada tehditlerin hedefi haline gelen bir gazetecinin öldürülmesiyle başlar. Olayın peşine düşen iki başkahramandan Karin geleneksel yöntemlere sahip tecrübeli bir dedektifken; Blue ise adli bilişim geçmişi olan genç bir stajyerdir. İki dedektif arasındaki bu karşıtlık esasında, teknolojideki eski doktrinler ile yeni dijital dünyanın gerektirdiği esnek yaklaşım arasındaki çatışmayı ima etmektedir. Filmde cinayet soruşturması sürerken, televizyonlarda iklim değişikliği sonucu soyu tükenmiş gerçek arıların yerine, üretimi hükümet tarafından desteklenen robotik arı projesine ${ }^{2}$ dair haberler geçmektedir.

Film ilerledikçe yaşanan cinayetlerin bu arılarla ve sosyal medyada yürütülen linç kampanyalarıyla bağlantılı olduğu anlaşılmaktadır. Öte taraftan tümüyle güvenli olduğu varsayılan bir otomasyon sistemi içinde geliştirilen drone arılar hack'lendikten sonra kontrol tümüyle kaybedilir ve Scholes adlı hacker'in yönetiminde yok edilecek hedef sosyal medya hashtag'leri üzerinden belirlenir. Buna göre Scholes'un ellerinde birer öldürücü silah olarak kullanılan arılar, öncelikle gündelik yaşamda yaptıkları hatalarla kitlelerin toplu nefretini çekerek sosyal medyada \#DeathTo (falancaya ölüm) hashtag'inin imlediği kişileri yok ederler. Gazeteci, şarkıcı ve diğerleri böyledir. Buna "sonuçlar oyunu" denmektedir.

Fakat filmin sonunda, yüz tanıma özelliği olan ve yapay zekayla donatılmış arılar,

\footnotetext{
2 Filmde resmedilen bu proje, esasında tümüyle hayal ürünü değildir. Harvard Üniversitesi bünyesinde Wyss Enstitüsü'nde "RoboBees" adlı gerçek bir proje üzerinde çalış1lmıştır. Detaylı bilgi için bkz. https://wyss.harvard. edu/technology/robobees-autonomous-flying-microrobots/
} 
bu yıkıcı hashtag'e yalnızca hedef olanları değil, onu yayarak onaylayanları da öldürmeye başlar. Yani birkaç gün önce gösterdikleri ağır tepki ve tehditlerle başkalarının ölümüne neden olan kişiler, tam da türettikleri nefret ve linç kültürünün ansızın kurbanları olurlar. $\mathrm{Bu}$ ölümcül aksine-dönüş, hacker'ın usül ve “Sonucun Dişleri” başlıklı 98 sayfalık manifestosunda belirginleşmektedir. Halkı zalimlikten zevk alan böceklere benzeten Scholes, manifestosunda şöyle demektedir: "Teknolojik devrim sayesinde öfke ve suçlama, sonucuna katlanmadan zehir yayma gücüne sahibiz. Sadece teknolojinin bize bahșettiği gücü tanımaya zorlandığımızda, bireysel sorumluluğumuzu anlamış oluruz". Filmin ana mesajına göre; linç kültürünün ardındaki kitlesel nefret, sosyal medyanın doğasıyla ilgilidir. Nitekim otonom-vari devamlılıkla işleyen sosyal medya, insan tepkilerini hem kitle psikolojisi, hem de ifade özgürlüğü yanılgısı içinde seri biçimde manipüle etmekte ve ansızın tümünü kontrolden çıkarabilmektedir.

\section{Sosyal Medya Kitlesi: Bireyselleşen Kitle, Kitleleşen Birey}

Sosyal medya — tıpkı filmde portrelendiği gibi- kitleyle ilgilidir. Halbuki bir tür kişiselleştirilmişlik görünümünde cereyan bu kitle hali, bireyi gücünü tam olarak idrak edemese de; varlığına inandırdığı amorf çoğunluğun içine katarak ona güç vermektedir. Bireylerin kitle içinde bireyselliklerini yitirip çözüleceklerini düşünen Bauman'1n (1998: 154) aksine Baudrillard (2014: 60) bu durumu, "kitlelerin bağrında yok olup gitmek ne hoş" sözleriyle ironikleştirmektedir. Ayrıca onu hem yalnız olmadığına, hem de tanımadığı başkalarıyla yekvücut olduğuna inandırmaktadır. Linç kültürünün arkasında bu gücün sağladığ1 tuhaf konfor vardır. Nitekim kitle, hedef aldığı kişi ya da grubun kimliğine hücum ederken de, kendi anonimliği içinde linçin diğer işbirlikçilerini bir şekilde örtbas etmektedir. Başka bir ifadeyle koro halinde yapılan suçlamalar, o koroya eşlik eden bireylerin özgün sesini belirsizleştirmektedir.

$\mathrm{Bu}$ anlamda her birey kitleseldir ve Anders (2018b: 225)'in solizm diye ifade ettiği kitle modeli tek başına birey gibidir: "Çağımızın, hizaya getirme ve sürüleştirme hedefi güden servisi, kitlenin kitle halinde yemlenmesi şeklinde değil, tek tek bireylere, elbette şişkin sayıda bireye sunularak hayata geçer ve yine tek tek bireyler tarafindan benimsenir. Kitleleşme solo gerçekleşir”. Milletlerin kaderini hükümdarların değil, kitlelerin belirlediğini savunan Gustave Le Bon (2018: 9)'un aksine denebilir ki; bugün kitleler topyekun milletleri hedef almamakta, detaylara inmek suretiyle bireyleri yakalayabilmektedir. Daha önemlisi, farklı işlere koşturulan farklı kitleler inşa edilmemekte; hangi konu olursa koşullandırmaya aç ve açık kitleler daima hazır bulunmaktadır. $\mathrm{Bu}$, sanal kitlelerin ayırt edici özelliklerinden yalnızca biridir. Sosyal medya kullanıcıları, her an aktif olmasa bile, her an kitlesel linçin parçası olabilecek donanımla birlikte yaşamaktadır. Filmde birinin linçine ortak olan polis memuru, bu olasılığı paradoksal biçimde temsil etmektedir.

İktidarların tek olmaması gibi (Barthes, 2015: 45), kitleler de kendi iç sistemlerindeki pragmatik tutkala rağmen çoğuldur; elbette çoğulcu olmamak kaydıyla. Kitlenin farklı olaylar karşısında tutarlı olması beklenmemektedir. Çünkü sosyal medyada herhangi bir kitlenin öyle ya da böyle bir parçası olan herkes, benzer tutarsızlı̆̆ın kurbanıdır. 
"Sosyal medya kitleleri”nin en belirgin özelliği misyoner, konjöktürel ve dolayısıyla geçici olmasıdır. Kitleyi saf şeytani hayvansılıkla makinemsi kör direncin birleşimi olarak formüle eden Zizek (2012: 16) de, kitlelerin sonsuz bir esneklikle parçalanıp, sonra tekrar bütün haline geldiklerini belirtmektedir. Şüphesiz bu, aralarında sarsılmaz bağların olduğu bir bütünleşme değildir. Şöyle ki linç gerçekleşip, hesap kapatıldıktan sonra kitlenin tüm üyeleri, birbirlerini bağlayan yeni bir gerekçe oluşana - belki de sonsuza - kadar dağılmaktadır. Dahası, aralarında şayet kaldıysa gerçek kitleler gibi sürdürülebilir bağlayıcı ortaklık da oluş(a)mamaktadır. Bu anlamda, filmdeki gibi sanal linç etrafında örgütlenen kişilerin, birbirlerini tanımaları gerekmemektedir.

Atomlaşmış parçaların ortak ve esasında belirsiz öteki'de buluşmasıyla oluşan kitlenin, bu nedenle bireylerin zor zamanlarda kendisine kaçabileceği bir sı̆̆ınak olduğu düşüncesi geçersizdir. Baudrillard (1991), kitleleri yönlendiren iktidarlardan bahsetse de (2012a: 93), aynı kitlelerin kontrol edilemeyecek denli başlarına buyruk ve bozucu olduklarını iddia etmektedir. Gerçekten de sosyal medya kitlesi, kendisine bile ait olamayacak kadar savruktur. Geçerli konjonktür dışında, söylemleri ve eylemleri arasında birliği sağlayacak muhkem bir değer yargısından mahrumdurlar. Onların bu merkezsizliği (Bauman, 2010: 18), üzerinde cereyan eden manipülasyonlara karşı bu denli açık ve savunmasız olmasının da nedenidir. Filmdeki hacker'in herkesi kolayca avlaması bununla ilgilidir. Kalıba sokulup biçimlendirilmiş olanların manipüle edileceğini vurgulayan Anders'in (2018a: 238) aksine denebilir ki, biçimsiz sanal kitleler başkasına ihtiyaç duymadan da kendilerini manipüle edebilmektedirler.

Sosyal medya kitlesi, birbirine fiziksel uzaklığın ürettiği zihinsel yakınlıkla bağlıdır. Nitekim yıllar önce kent kalabalıklarını yorumlayan Simmel (2015: 31), kentlerdeki zihinsel mesafenin kaynağı olarak bedensel yakınlığı ve mekan darlığını işaret etmiştir. Siber-uzamda herhangi mekansal darlık olmadığı gibi, bedenler de kendilerini teşhir etmedikleri sürece birbirinden haberdar bile değildir. Sosyal medyadaki belki de tek beden bu mecranın kendisidir ki o da kitleleri deşarj ettiği oranda geniş ve işlevlidir. Popüler kültürün değerleri etrafında belirlenen tüketimci-normları yeniden üreten bu sanal kitleler, gücünü de ağırlıkla bu mekaniği temsil eden nicelikten almaktadır. Bunun sonucu olarak sosyal medyada etki, söylemin derinliğiyle değil; fazla dolaşımıyla ilgilidir. Bunun için süreci en isabetli tespitler yerine; en fazla etkileşim alan paylaşımlar belirlemektedir. Filmde de hakkında en fazla etkileşim alan kişiler öldürülmektedir.

Her türlü kabalık, sanal kalabalıkların ellerinde sanki zaten gerekliymiş gibi görünen meşru bir tepki olarak kodlanmaktadır. Kitlenin yüzünün olmadığını bildiren Bauman (1998: 154), normalde kendi başına suç işleyemeyecek bir kullanıc1-bireyin, kitle içinde o suçu kolaylıkla işleyebileceğinden bahsetmektedir. Çünkü kitle; suçun öznesini nesneleştirmektedir. Elias Canetti(2014: 18)'ye göre kitle; salt deşarj olma arzusuyla toplanan bedendir. Bunun dramatik bir uzantısı olarak, sanal kitlenin parçaları olan bireyler arasındaki nitelik farkı sıfırlanmaktadır. Çünkü kitleye dâhil olmanın tek şartı vardır. O da Bauman (2017: 163)'ın saptadığı gibi, kitle içinde diğerlerinin yaptıklarını yapmayı sorgusuzca sürdürmektir. Üstelik bunu makul ve güzel diye değil, sırf onlar yapıyor diye yaparak sürdürmek. 


\section{Sosyal Medya, Asosyal Linç: İfadenin Özgürleşmesinden Nefretin Özgürleşmesine}

Kullanıcılarının dikkatleriyle beslenen sosyal medya, onların dikkatlerini gasp ederek çoğu kez anlık gaf veya zafiyetlere dayalı sansasyonlar üretmektedir. Pettman (2017: 67) da sosyal medyada kesintisiz dikkatin hayati olduğunu, aksi halde örneğin; dikkatsizlik sonucu önceden paylaşılmış bir hikaye veya videonun yeniden paylaşılmasının kullanıcının itibarını zedeleyeceğini ya da dikkatli olmayıp bir mikro olayı kaçırmak suretiyle geride kalınabileceğini ifade etmektedir. Dikkat, sanal takipçilerin dünyasında kullanılan ürünün bedeli olarak ödenen yeni ücret formudur (Wu, 2017: 399). Doğrusu uzun yıllardır içinde yaşadığımız aşırılıklar toplumunda, enformasyon bolluğunun dikkati sömürerek bir çeşit dikkat kıtlığı oluşturduğu konuşulmaktadır (Simon, 1971: 40). Sonuç olarak bollukla tüketilmiş olan dikkat, eylemlerin sorumluluğunu üstlenecek ahlaki hassasiyet ve bilince ket vurmaktadır. Bozulan bir toplumda nefret, normal görülen bir noktada her yeri ve herkesi kuşatana kadar görmezden gelinip nötralize edilebilmektedir (Putri ve Nafisah, 2020: 102). Ta ki sorgulamadan gittiği yolun çıkmaz sokak olduğunu gerçeğini bizzat ödeyeceği bedelle yüzleşene kadar. Filmde bu bedel, ölümle -yani geri dönüşsüzlükle- ifade bulmaktadır.

Sosyal medya; teknik anlamda hızın esas olmasının dışavurumu olarak bireyleri önce ve genellikle sloganlarla kitle-söylemine dahil edip, daha sonra söylem üzerine düşünmeye bile fırsat vermeyecek sürgit ileti sağanakları altında bırakmaktadır. Le Bon(2018)'un tasavvurunda basit hislere kapılıp kolay tahrik olabilen kitleler, şüphe duyma ve hüküm verme konusunda da yetersizdirler. Sosyal medya kitleleri de ekranlarına düşen ve ilgi alanlarını yakalayan her görüntü hakkında kolay hükümler vermektedir. Gerçekten de "sibermekân cennetinde verilen hükümlerin temyizi yoktur" (Bauman, 2016: 26). Adorno (2011: 64), kitlelerin kendilerini köleleştiren ideolojilerde ssrarc1 olduklarını öne sürmekte ve bu kötücül sevginin yetkili mercilerin kurnazlığını bile geride bıraktığını belirtmektedir. Bu ısrar hakkındaki tespiti yerinde olsa da; Adorno'nun düşüncesine temel teşkil eden köle-iktidar diyalektiği güncel realitenin uzağındadır. Zira sosyal medya kitlesi, kendisinin köleleştirildiğini fark edemeyecek denli kendinden geçmiş [intoxicated] vaziyettedir. Burada harcanan her saniye, yapılan her paylaşım çoğu kez tam olarak neye olduğunu bilemediği bir bağımlılığın üzerine kurulmaktadır. Bu yüzden belki burada benliğine sinmiş bir iktidar; dolayısıyla da kendisine yönelmiş bir kölelik ilişkisi vardır. Buna rağmen kitlelerin genel olarak olan bitene dair bir anlam çabası da yoktur (Baudrillard, 1991: 32). Onlar gösteri peşindedirler ve içeriği de ancak gösteri formunda tanıyıp yaşamaktadırlar (Baudrillard, 1991: 17).

Tuhaf bir şekilde sanal linçin arkasındaki kolektif nefret, ortak bir gösterinin coşkulu katılımcıları gibi kullanıcılar arasındaki en muhkem birleştirici rolü üstlenmektedir. Daha önce vurgulandığı gibi, ortak bir öteki, diğer tüm sanal değişkenler arasında kitle-duygularını en fazla harekete geçiren motivasyon kaynağı olmaktadır. Adorno (2005: 25)'nun özetlediği şekli ile, “doğru nesneyi bulamayanın sevgisi, kendisini ancak yanlış nesneye duyduğu nefretle ifade edebilmekte ve bu da onun nefret ettiği şeye benzemesine yol açmaktadır”. Bu açıklamaya göre; öteki'ye yönelen linçin çıkış noktası, yine kullanıcının kendisidir. Bu, belki de bir tür öz-savunma mekanizmasının yansımasıdır. Baudrillard (2001: 80)'da, ötekinin zayıflığına karşı kendimizi yapay 
nefretle koruduğumuzdan bahsetmektedir. Ayrıca, nefretin sevgiden çok daha güçlü bir biçimde insanları birbirlerine bağladığını söylemektedir (Baudrillard, 2001: 116). Uzlaşma yolunun şiddet, savaş ve bayağılık olduğu bu medya kültürü (Baudrillard, 2014: 255), bir tarafın kurtuluşunu, daima öteki'nin yıkımı üzerine inşa etmektedir. Oysa bu, sürekliliği olan bir kurtuluş değildir. Yıllar önce, "hepimiz, yiyecekleri başkaları olan sanal yiyicileriz" diyen Anders (2018b: 260), halihazırda sembolik olarak obez olan ve yedikçe acıkan sanal kitlelerin bugününü öngörmüş gibidir.

Sosyal medya ve linç arasındaki simbiyotik ilişkinin arkasındaki bir diğer önemli kavram; şeffaflıktır. Aşırı paylaşma talebinin merkezileştiği siber-uzam, kullanıcı-bireyleri gönüllü olarak değil; bağımlı olarak katıldıkları kişisel veri endüstrisinin hem sermayesi, hem de ortağı yapmaktadır. Dağınık parçalardan oluşsa da, kişinin kendi dilinden anlattığı hikayelerden bile güvenilir olduğu düşünülen "kişisel veriler" (Bauman ve Lyon, 2018: 19) daima tehdit altındadır. Çünkü bu şeffaf evrende ya da şeffaflık evreninde, tüm pazarlama söylemlerinin aksine "kişisel" diye bir şey yoktur ve hiçbir zaman da olmayacaktır. Bireylerin uyandıkları andan yatağa gittikleri ana kadar yaşamlarındaki tüm detayları ihtiva eden bu kişisel verileri cesurca — yoksa düşüncesizce mi denmeli? paylaşmaları, doğrusu tam da içinde yaşadığımız çağa özgü insanlık durumudur (BarrettMaitland ve Lynch, 2020).

Paylaşmanın kendisi, paylaşılan duygular arasında en önde gelir - tüm diğer duyguların önüne geçen, diğer duyguların incelenmesine yer ya da zaman bırakmayan - duyguların en karşı konulmazıdır ... Paylaşma şimdi, burada, tam önümüzdedir. Birinden bir ötekine giden yol eskiden uzundu; şimdi biz, yani ben'in çoğulundan başka bir şey olmayan biz evreninde artık hiçbir mesafe, hiçbir gedik ve delik kalmamıştır, hiçbir köprünün kurulmasına ihtiyaç yoktur. (Bauman, 2011: 160-161).

Paylaşma zorbalığı ve onun ardında teşvik edilen şeffaflık ve ifşacılık, linçe uğramanın ve linç etmenin öncülüdür. Han (2020b: 20)' a göre de pasif seyircilerin organize ettiği şeffaflık talebi, maskeleri düşürmek ve skandal yaratmak içindir. Yazarın "seyirci demokrasisi" olarak tanımladığı bu işleyiş, şikayetçi ve yakınmacı bir katılımı önermektedir. Tabi ki burada bağımsız ve otantik bir seyircilikten bahsetmek artık mümkün değildir. Aksine, bu yolla derinden derine alternatif bir adalet sistemi işletilmektedir.

Filmde de gösterildiği gibi, sosyal medya linçleri yeri geldiğinde gerçek hayattaki adalet sistemini baypas etmenin de yöntemi olarak belirmektedir (Maya, 2020: 129). Bir sorun insanlarda derinden yankılandığında, sosyal medya değişim yaratmak için toplumsal güçlerini bir araya getirmelerine olanak tanımaktadır. Ronson'a göre (2015), gerçek yaşamda adaletin yerine geldiğini göremeyen mağdurlar bu mecrada kabul görüp, intikam alabilmektedir. Üstelik bunu yapmak için herhangi yasal mevzuatlara uymalarına ve çetin prosedürlerden geçmelerine gerek de yoktur. Tanıklar dinlenmeden, deliller ortaya konmadan, taraflar kendilerini savunmadan nihai hükme varılmaktadır. Yani sosyal medyadaki [sanal] mahkeme, gerçeğinin tam aksine, sanığın yargılanmasından önce ve cezalandırılmasından sonra kurulmaktadır. Sosyal medyadaki linç kültürü, linç biçimleri arasında en örtük, en hızlı ve en pratik ${ }^{3}$ olanıdır.

3 Watt-Smith'e göre (2020: 73) bu pratiklik, mecraya ilişkin ahlaki açmazların özüdür. 


\section{Mobil Teknolojiler: Kesintisiz Çevrimiçi Olmanın Tekinsizliği}

Mobil teknolojiler; dünyayı fiber ağlarla ören internetin açtığı ufuktan beslenerek, sosyal medya kullanımını zaman ve mekan sınırsızlıklarından muaf kılmıştır. Elbette ilk bakışta bir tür lütufmuş gibi görünen bu muafiyet, öte taraftan sanal şiddetin haritasını da belirsizleştirmiş, ifade özgürlügünün sınırlarını şiddetinkisiyle kesiştirecek şekilde sonsuzlaştırmıştır. Bu nedenle linç kültürü ile akıllı telefonlar başta olmak üzere mobil teknolojiler arasında dikkat çekici bir ilişki vardır. Normal şartlarda siber uzamın dışında başına buyruk gezinen beden, bugün itibariyle kendisine tıpkı yeni bir uzuv gibi eklemlenen mobil teknolojilerin hakimiyeti altına girmiştir. Han (2018b:15)'ın dediği gibi, data ve objelerin eklentisi olan beden dijital sensörlerle donatılmış, bir tür mobil enformasyon terminaline dönüştürülmüştür. Bunun sonucu olarak bedenin her eylemi, eşzamanlı biçimde ve tekniğin şeffaflaştırıcı mantığına uygun olarak kendiliğinden ifşa olmaktadır. Bu noktada kablosuz ve mobil dünyanın enerjik nesillerini, "taşınabilir elektronik itiraf hücreleri ile donanmış ergenler" (Bauman ve Lyon, 2018: 43) olarak tanımlamak çok da akıldışı durmamaktadır.

İletişim teknolojilerinin bedenine ve benliğine bu denli bitişik olması, kişiyi ağa bağlı olan aygıtın önce kullanıcısı, sonra da kendisi yapmaktadır. Aygıt-insanları birbirine bağlayan ve aralarında ilişkisiz iletişim kurmalarına olanak veren sistem- Bauman (2012: 39)'ın aydınlattığı gibi, bunları esasında zamansız ve mekansız olarak birbirlerinin emrine amade yapmaktadır. Yeri geldiğinde hayati olabilen mesafeleri işlevsizleştiren bu yeni birliktelik rejimi altında inzivada veya uzakta olmak imkansızlaşmaktadır. A $\breve{g}$, artık araçlar arasında değil; insanlar arasında tasarlanmaktadır. Benzer şekilde 7/24 çevrimiçi olan akıllı telefon, kendisini değil; sahibini sisteme entegre etmektedir, üstelik onun tüm ilgi ve beğenilerini kalıcı olarak kodlamaktadır. Virilio (2003: 67); yarı-zamanlı değil, sıfır-zamanlı iş sözleşmelerinin yanında kişilere verilen cep telefonlarını örnek göstererek, 'hane içi köleliğin bu yeni icadı'nın kişiyi devamlı işe koştuğunu anlatmaktadır. Buradaki iş kavramı sadece endüstriyel çalışmaya indirgenmemelidir. Nitekim çevrimiçi birey tatildeyken de, uyurken de iş yapmaktadır.

Sosyal medya linçlerini tümüyle olağanmış gibi gösteren algının ardında; biraz da mobil teknolojilerin kendisini gizlemesine ve sanki yokmuşçasına konumlanmasına olanak tanıyan küçük ve yalın tasarımı vardır. Nitekim akıllı tercihlerle yaşanan anındalık çağında iri hacimli, katı ve ağır şeylerin kısıtlayıcılığı yerine; yeni göçebeliği temsil eden cep telefonları, taşınabilir ve kullanıp atılabilir aygıtlar gibi kültürel simgelerin hakimiyeti esastır (Bauman, 2019: 192). Birer özgürlük göstergesiymiş gibi pazarlanan bu simgeler, "araçların dışında kalma"nın topyekûn "dışarda ve geride kalma" anlamında okunduğu tersten-otokratik bir düzeni çağrıştırmaktadır. Bu açıdan belki de teknoloji formunda linçin ilk aşaması onu kullanmama tercihi veya eğilimi gösterenler üzerinde uygulanmaktadır. Leonhard da (2018: 181) bağlantıyı kesenin ve kişisel verileri paylaşmayı reddedenin önce toplum, sonra da sistem tarafından cezalandırılmaktan kurtulamayacağını ifade etmektedir.

Mirani ise (2021: 176), Leonhard'ın aksine, mobil teknolojiler hakkında getirilen eleştirileri bağnazlık ve ufuksuzlukla ilişkilendirdikten sonra, bu mecralarda gezinenlerin esasında bütün renkleriyle dünyayı gözlemlediklerini, ona katıldıklarını iddia etmektedir. 
Mirani'nin bu yorumlaması, her şeyden önce, siber-uzamdaki renklerin ve dünyanın sanrılarla dolu olduğu fikrini göz ardı etmektedir. İkinci olarak Mirani, burada kalıcılığ 1 ve derinliği esas alan bir ilişkinin yaşandığını varsaymaktadır. Ne var ki sanal ilişkideki dijital bedenler; birbirleriyle ancak haz veya nefret duygusu yükseldiğinde ilişkiye geçmektedirler. Bu açıdan özellikle sanal linç ekseninde mobil teknolojilerin rolü oldukça kayda değerdir. Han (2020b: 22), akı1lı telefonları "kutsal nesne"ler olarak tanımlarken, cep telefonuna tespih gibi yaklaşan kullanıcıların aktif ritüellerini ${ }^{4}$ öne çıkarmaktadır.

Sosyal medya kültüründe kullanıcı bireylerin en büyük zafiyetleri; en çok bağımlısı oldukları şeylere dairdir. Fakat buradaki zafiyet salt kullanıcının değil; söz konusu mecranın da açık yarasıdır. Çünkü her şeyin popülerleşmek adına teşhir edildiği bu uzam, tümüyle bağlantıdan ibarettir ve Goodman (2016: 340)'ın dediği gibi, bağlantı arttıkça açık da artmaktadır. Gözlediğimiz nesnelerin aynı zamanda gözleyici de olmaları (Han, 2020b: 69), bu riskin boyutlarını genişletmektedir. Örneğin; mobil teknolojilerindeki "kişisel”lik görünümü, bu riskin sonucu olarak ansızın kaybolabilmektedir. Bu anlamda bu teknolojiler; olanca esnekliğine rağmen kırılgan, olanca şeffaflığına rağmen tekinsizdir. Bu kırılganlık ve tekinsizliğin metaforu, analiz edilen filmde de gösterildiği gibi, hack'le(n)medir. Hack kültürü, sosyal medyada sır modunda söylenen her "kişisel" paylaşımın aslında bir tür "dünyaya açma" edimi olduğunu, bizzat mecranın tekinsizliği gerçeğinin üstünden geçerek tescil etmektedir. Yani burada insanı var eden sırlar, tıpkı filmin sonu gibi, an içinde onu yok da edebilmektedir.

\section{Sonuç}

Sosyal medya mecraları, sayısız iletiye ve görsele rağmen sonsuz bir iştahla sansasyon açlığı çekmektedir. Bu açlık, linç süreçlerine dâhil olan herkesi aynı suçun eşit ortakları yapmaktadır. "Bizler" der Baudrillard (2012b: 29-30), "bu tekelleşmiş küresel ağların içinde yüzen rehineleriz. Aynı zamanda hem kurban, hem de suç ortağı konumundayız. Egemenlik düzeninin en büyük kurnazlığıysa bu tekelin kimsenin denetiminin altında bulunmamasıdır. Olan biten bütün bu iyi ya da kötü şeylerden hiç kimse, hiçbir birey, devlet ya da yasal süreç sorumlu tutulamaz". Başka bir yerde, bizlerin artık gerçeğin oyuncuları değil; sanalın iki yana çalışan ajanları olduğumuzu öne sürmektedir (Baudrillard, 2010: 126). Bu sorun, filmde şu sözlerle karşılık bulmaktadır: "Birisinin ölmesini umarsızca istiyorsan; senin için birinin hayatı o kadar basitse, bir klavye uzaklığındaysa, sende ölmeyi hak ediyorsundur. Böylece dünyada ne kadar kötülük olsa da, sadece iyilikle karşılık veren insanlar hayatta kalır”.

Han (2020a: 54), “dijital mahalle” olarak tanımladı̆̆ 1 sosyal medyanın yalnızca hoşa gidecek şeylerin sunulduğu mahrem bir alan olduğunu öne sürmektedir. Oysa öncelikle buradaki "mahalle" kavramı, müphem dijital kültür için hala belli bir mekansallığın varlığında israr etmektedir, ki bizce artık böyle bir adresten artık bahsedilemez. İkincisi; burada "hoşa gidecek şeylerin" değil; bize göre "şeylerin hoşa gidecek şekilde" sunulması esastır. Üçüncüsü; yine burada rahatlıktan bahsetmek de güçtür. Kullanıcılar bu ağda -yani

4 Byung Chul-Han bu kutsal nesne benzetmesinin devamında akıllı telefonu günah çıkarma sandalyesi olarak betimlemektedir (2020b: 22). Fakat bizce buradaki günah çıkarma eylemi, kapalı kapılar ardında değil; sosyal medyada kamusal olarak ve genellikle gösteri/ş kültürünü yeniden üretecek şekilde gerçekleştirilmektedir. 
kaygan şimdi' lerin ortasında- mutlak mahremiyetle kesin bir rahatlığa kavuşmak bir yana, sanallığın belirsizliğinde sürekli olarak daha fazla mahremiyet çözülümüne ve daha fazla yorgunluğa duçar olmaktadırlar. Zaten ağın, kullanıcılar dünyasındaki tüm albenisi, belki de hiçbir zaman gerçekleşmeyecek olan bu zımni tatminsizlik duygusuna dayanmaktadır. Bunun sonucunda; her tatminsizlik yeni bir hınç ve huzursuzluk olarak kendi küllerinden doğmaktadır. Ağ'ın neden olduğu ve kullanıcının benliğinde büyüyen bu hınç duygusu, kolayca ve muhakkak öteki'ne yönelmektedir. Modern dış dünyanın deneyimi olan sanal linç kültürü, bu kadim içsel kısır döngünün sonucu ve yeni versiyonudur.

Sanal linç örnekleminde görüldüğü gibi, sosyal medya kendi gerçeklik uzamını tasarlamakta ve yaşatmaktadır. Bu kendine özgü yeni gerçeklik, asırlardır bildiğimiz gerçekten oldukça farklıdır. Dahası bilinen gerçek ve gerçeğin son kalesi olarak görülen beden, artık bu yeni gerçekliğin hem hizmetçisi, hem deneği, hem de ayak bağıdır. Fakat kullanıcılar için bu, her nasılsa ciddi bir sorun olarak görülmemektedir. Baudrillard (1995: 71) artık hiçbir şeyin bizleri tiksindirmediğini söylerken, kastettiği olgunun günümüze izdüşümü belki de budur. Modern birey, içinde yaşadığımız çağda, kanımızca yalnızca teknolojik hızını kısıtlayan şeylere karşı tiksinti duymaktadır. O önündeki ekranla ve benliğinde beliren engellenemez sanal coşkuya rağmen, daima asosyal kıpırtısızlık halindedir. Her şeyi ekranı, her yeri odası yapmış bu mekansızlık mekanında hiçliği tavaf etmektedir. En derin acılar bile, bu mecradaki sanal bedeninde yalnızca bir "bakış" miktarı yer tutmaktadır. Daha sonra ufak bir parmak hareketiyle bu bakışı da öteleyip; sonsuz yeni görüntülerin dünyasında yitiğini aramayı sürdürmektedir.

Sosyal medya gözün devamlı açık ve dinamik olmasını dayatmaktadır. Bakış daimi, takip sürekli olmalıdır. Ne var ki gözün bu zoraki açıklığı, arzulanan tefekkürün yitimidir. Çünkü tefekkür, Pallasmaa (2016: 56)'nın altını çizdiği gibi, düş kurarken veya müzik dinlerken yaptığımız gibi görme duyusunun kapatılmasını gerektirmektedir. Oysa bu mecrada sörf yapan kişinin dişı sessizliğe bürünse de; zihni daima gürültülü ve dağınıktır. Zira Han (2019b)'ın teşhis ettiği şekilde, paylaşımlardan oluşan yığılma gürültüyü arttırmaktadır. Oysa tefekkür, içinde huzur ve sessizliğin birleştiği sükûneti gerektirmektedir. Alain de Botton (2015: 17) da bunun önemini ve dolayısıyla güçlüğünü şöyle özetlemektedir: "artık bir dakikalık bir sükûnet ne büyük bir başarı sayılıyor; dikkatimiz dağılmadan uykuya dalmak ya da bir arkadaşımızla sohbet etmek nasıl da bir tür mucizeye dönüştü ve haber girdabından bir günlüğüne olsun uzaklaşıp yağmurun ve kendi düşüncelerimizin sesi hariç hiçbir şeyi dinlememek, nasıl keşişlere özgü bir disiplin gerektiriyor". Buna göre linç kültürünün çözümüne yönelik bu sükûnetin kazandırılmasında ve kolektif hıncın arındırılmasında gözü kapatmak bakıştan; tefekkür bilgiden; duyarlılık da farkındalıktan anlamlıdır.

Unutmamak gerekir ki; sosyal medya kitlesinin yürüttüğü linç, mecranın özsunumunun aksine hiç de sanal değildir. Burada(n) insanlar veya gruplar üzerinde yürütülen linç kampanyaları sonunda, insanlar "gerçek" hayatlarıyla ilgili "gerçek" kararlar almaya zorlanmaktadır. Linç sürecine katılanlar, sosyal medyanın özgürlük yanılsamas1 altında "olumluluğun şiddeti"ni ${ }^{5}$ yürütür görünseler de (Turan, 2017: 129); buradaki şiddet, olumluluğun gerektirdiği gizlilikten uzaktır. Aksine, sanal kitle,

5 Byung Chul-Han'ın “olumluluğun şiddeti” ifadesi, açıkça görünmeyen ve yıkıcı olarak da algılanmayan şiddet formunu işaret etmektedir (2018a). 
uyguladığı şiddeti apaçık ve aralıksız biçimde teşhir etmekte ve kendisi hakkında oluşan duyarsızlaşmayı tekrarlı-görünürlük üzerinden sağlamaktadır. Bu, sürekli seri-devinimde olan bir şeyin görünürlüğünü algısal olarak yitirmesi gibidir. Mecra hakkında beliren "hafızasızlık" izleniminin sebebi de bu hız-görüntü yanılsamasıdır. Ne var ki geçiciliğin izlenimleriyle yüklü olan mecrada, gerçekte derin bir kalıcılık söz konusudur. Paylaşılan her şey tüm detaylarıyla mecranın belleğine akmakta ve büyük veri yığınları işlenerek, tanımlayıcı bilgi çıktıları olarak pazarlanmaktadır.

Dijitalin belleğinde mutlak anlamda silmeye ve unutmaya yer yoktur. Yazılmış her söz, paylaşılmış her fotoğraf, gerekli olduğunda yeniden kullanılacak şekilde daima tetikte beklemektedir. Filmde görüldüğü gibi, uzamın öteki ucundaki - ki orası ağ' 'n ulaştığı her yerdir - birini devre dışı bırakmak için, sıradan bir klavye teması yetmektedir. Klavye, bu çağın giyotinidir. Üstelik yakında bunun için "dokunma"ya bile gerek kalmayacaktır. Ufak bir parmak hareketi ya da zihinden ansızın geçirilen bir düşünce ve hatta belki de refleks, kimliği belirsiz ama gerçek kişilere yaşamı dar edecektir. Ve muhtemelen o kişi için kaçacak bir köşe ya da sığınılabilecek bir inziva mekânı olmayacağı gibi; az önce tık'layan kişi de sıranın kendisine gelmesinden de kurtulamayacaktır. Çünkü sanal linç; linçin öznesi olan ama nesnesiymiş görünen kişinin kendisiyle ilgilidir. Linç; onun açmazlarıyla başlamakta, onunla sürmekte ve er ya da geç onda son bulmaktadır.

\section{Kaynaklar}

Adorno, Theodor W., (2005). Minima Moralia, Çev., Orhan Koçak, İstanbul: Metis Yayınları.

Adorno, Theodor W., (2011). Kültür Endüstrisi - Kültür Yönetimi, Çev., N. Ülner, M. Tüzel ve E. Gen, İstanbul: İletişim Yayınları.

Aloğlu, Ebru, (2018). "Sosyolojik Perspektiften Linç ve Toplumsal Şiddet Sarmalı”, Sosyoloji Dergisi, (38), s. 219-230.

Barrett-Maitland, Nadine ve Lynch, Jenice, (2020). "Social Media, Ethics and the Privacy Paradox" https:/www.intechopen.com/online-first/social-media-ethics-andtheprivacy-paradox. Erişim Tarihi: 10 Haziran 2021.

Barthes, Roland, (2015). Bir Deneme Bir Ders: Eiffel Kulesi ve Açılış Dersi, Çev., M. Rifat ve S. Rifat. İstanbul: Yapı Kredi Yayınları.

Baudrillard, Jean, (1991). Sessiz Yığınların Gölgesinde Toplumsalın Sonu, Çev., Oğuz Adanır, Ankara: Doğu Batı Yayınları.

Baudrillard, Jean, (1995). Kötülüğün Şeffaflı̆̆ı: Aşırı Fenomenler Üzerine Bir Deneme. I. Ergüden (Çev.). İstanbul: Ayrıntı Yayınları.

Baudrillard, Jean, (2001). Tam Ekran, Çev., B. Gülmez, İstanbul: Yapı Kredi Yayınları.

Baudrillard, Jean, (2010). Cool Anılar III-IV, Çev., Yaşar Avunç, İstanbul: Ayrıntı Yayınları. 
Baudrillard, Jean, (2012a). Kusursuz Cinayet, Çev., N. K. Sevil, İstanbul: Ayrıntı Yayınları.

Baudrillard, Jean, (2012b). Karnaval ve Yamyam, Çev., O. Adanır, İstanbul: Boğaziçi Üniversitesi Yayınları.

Baudrillard, Jean, (2013). Amerika, Çev., Y. Avunç, İstanbul: Ayrıntı Yayınları.

Baudrillard, Jean, (2014). Cool Anılar I-II 1980-1990, Çev., A. Sönmezay, İstanbul: Ayrıntı Yayınları.

Bauman, Zygmunt ve Lyon, David, (2018). Akışkan Gözetim, Çev., E. Yılmaz, İstanbul: Ayrıntı Yayınları.

Bauman, Zygmunt, (1998). Sosyolojik Düşünmek, Çev.,A. Y1lmaz, İstanbul: Ayrıntı Yayınları.

Bauman, Zygmunt, (2010). Etiğin Tüketiciler Dünyasında Bir Şansı Var mı?, Çev., Funda Çoban, İstanbul: De Ki Basım Yayım.

Bauman, Zygmunt, (2011). Postmodern Etik, Çev., A. Türker, İstanbul: Ayrıntı Yayınları.

Bauman, Zygmunt, (2016). Küreselleşme: Toplumsal Sonuçları, Çev., A. Yılmaz, İstanbul: Ayrıntı Yayınları.

Bauman, Zygmunt, (2017). Postmodern Etik, Çev., A. Türker, İstanbul: Ayrıntı Yayınları.

Bauman, Zygmunt, (2019). Akışkan Modernite, Çev., S. O. Çavuş, İstanbul. Can Yayınları.

Botton, Alain de, (2015). Haberler: Bir Kullanma Kılavuzu, Çev., Zeynep Baransel, İstanbul: Sel Yayıncılık.

Brooker, Charlie, (2011). “The Dark Side of Our Gadget Addiction”. The Guardian. 1 Aralik 2011. https://www.theguardian.com/technology/2011/dec/01/charlie-brookerdark-sidegadget-addiction-black-mirror. Erişim Tarihi: 06.06.2021.

Brooker, Charlie, Jones, Annabel ve Arnopp, Jason, (2018). Inside Black Mirror, London: Penguin Random House.

Canetti, Elias, (2014). Kitle ve İktidar, Çev., G. Aygen, İstanbul: Ayrıntı Yayınları.

Castells, Manuel, (1996). The Rise of the Network Society, The Information Age: Economy, Society and Culture Vol. I. Malden, MA; Oxford, UK: Blackwell.

Craven, Paul ve Wellman, Barry, (1973). “The Network City”, Sociological Inquiry. 43 (3-4). S. 57-88.

Datareportal (2021). "Digital 2021: Global Overview Report", 27 Ocak 2021, https://datareportal.com/reports/digital-2021-global-overview-report. Erişim Tarihi: 6 Haziran 2021. 
Demir, Sertaç Timur, (2021). Büyüyen Veri Küçülen İnsan: Şimdileşen Geleceği Kara Ayna'da Seyretmek. TRT Akademi, 6 (11), 88-105. DOI: 10.37679/trta.816681

Diken, Bülent ve Laustsen, Carsten B., (2008). Sociology through the Projector, London: Routledge. Yayınları.

Ellul, Jacques, (2003). Teknoloji Toplumu, Çev., M. Ceylan, İstanbul: Bakış

Goodman, Marc, (2016). Geleceğin Suçları: Dijital Dünyanın Karanlık İki Yüzü, Çev.,C. Özdemir, İstanbul: Timaş Yayınları. Yayınlar1.

Han, Byung Chul, (2018a). Şiddetin Topolojisi, Çev., D. Zaptçığlu, İstanbul: Metis

Han, Byung Chul, (2018b). Güzeli Kurtarmak, Çev., K. Filiz, İstanbul: İnsan Yayınları.

Han, Byung Chul, (2019a). Zamanın Kokusu: Bulunma Sanatı Üzerine Felsefi Bir Deneme, Çev., Ş. Öztürk, İstanbul: Metis Yayınları. Yayınları.

Han, Byung Chul, (2020a). Şeffaflık Toplumu, Çev., H. Barışcan, İstanbul: Metis

Han, Byung Chul, (2020b). Psikopolitika: Neoliberalizm ve Yeni İktidar Teknikleri, Çev., H. Barışcan, İstanbul: Metis Yayınları.

Hiltz, Starr Roxanne, ve Turoff, Murray, (1978). The Network Nation. Reading, MA: Addison-Wesley.

Le Breton, David, (2016). Bedene Veda, Çev., A. U. Kılıç, İstanbul: Sel Yayıncılık.

Leonhard, Gerd, (2018). Teknolojiye Karşı İnsanlık: İnsan ile Makinenin Yaklaşan Çatışması, Çev., C. Akkartal ve İ. Akkartal, İstanbul: Siyah Kitap.

Martin, James, (1978). The Wired Society, N. J.: Prentice Hall.

Maya, Aline, (2020). Hated in the Nation and \#DeathTo: What are the Consequences of Trial by Twitter?, İçinde David K. Johnson (Ed.). Hoboken, NJ : Wiley-Blackwell.

Mirani, Leo, (2021). 'Kişisel Teknoloji Gerçekten Kişisel Oluyor'. D. Franklin (Ed.). Mega Tech-2050'de Teknoloji, Çev., B. Şeyrek, İstanbul: Kolektif Kitap, s. 165176.

Pallasmaa, Juhani, (2016). Tenin Gözleri, Çev., A. U. Kılıç, İstanbul: YEM Yayın.

Pettman, Dominic, (2017). Sonsuz Dikkat Dağınıklığı: Gündelik Yaşamda Sosyal Medyaya Odaklanmak, Çev., Y. Çetin, İstanbul: Sel Yayıncılık.

Putri, Sheila, Adena, ve Nafisah, Nia (2020). Construction of Dystopia in Black Mirror: Hated in the Nation, Passage, 8 (1). 87: 103.

Ronson, Jon, (2015). So You've Been Publicly Shamed. New York: Riverhead Books. 
Sennett, Richard, (2013). Kamusal İnsanın Çöküşü, Çev., S. Durak ve A. Yılmaz, İstanbul: Ayrıntı Yayınları.

Simmel, Georg, (2015). Modern Kültürde Çatışma, Çev., T. Bora, U. Özmakas, N. Kalaycı, E. Gen, İstanbul: İletişim Yayınları.

Simon, Herbert A., (1971). Designing Organizations for an Information Rich World. In M. Greenberger (ed.), Computers, Communications, and the Public İnterest, s. 37-72.

Sutherland, J-A ve Kathryn M. F. 2013. Cinematic Sociology: Social Life in Film, Thousand Oaks, CA: Sage.

Turan, Hatice, (2017). Sosyal Medya'da Şiddet: Sağduyunun Yitiminde Başkalık ve Kendilik Deneyimleri. Marmara İletişim Dergisi, (27), s. 121-133.

van Dijk, Jan, (1991) De Netwerkmaatschappij: Sociale aspecten van nieuwe media, Houten: Bohn Staflen van Loghum.

Virilio, Paul, (2003). Enformasyon Bombası. İ. Şahin (Çev.). İstanbul: Metis Yayınları.

Watt Smith, Tiffany, (2020). Schadenfreude: Başkasının Talihsizliğinden Duyulan Keyif, Çev. N. Bingöl, İstanbul: Kolektif Kitap.

Wu, Tim, (2017). Dikkat Tacirleri. Çev., B. Karal, İstanbul: The Kitap Yayınları.

Zizek, Slavoj, (2012). İdeolojinin Aile Miti, Çev., M. Yıldırım, İstanbul: Encore Yayınları.

Araştırmacı Katkı Oranı: Araştırmacılar çalışmaya eşit oranda katkı sunmuştur.

Destekleyen Kurum/Kuruluşlar: Herhangi bir kurum/kuruluştan destek alınmamıştır.

Çıkar Çatışması: Herhangi bir çıkar çatışması bulunmamaktadır. 